\title{
Diabetes Mellitus and the Lungs
}

\section{Canan Ozyardimci Ersoy}

Division of Endocrinology and Metabolism, Department of Internal Medicine, Bursa Uludag University Faculty of Medicine, Bursa, Turkey

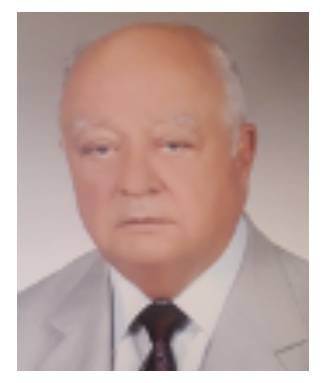

This paper is dedicated to the memory of Professor Doctor Nihat Ozyardimci, born in $1^{\text {st }}$ March 1937 and passed away in $18^{\text {th }}$ July 2018, who devoted his life to scientific studies and patient care in chest diseases and tuberculosis. He was one of the distinguished leaders in this field in Turkey.

\begin{abstract}
Diabetes mellitus is a chronic disease characterized by hyperglycemia causing damage to the vascular system. The lungs with a large vascular network are also predisposed to diabetes' vascular damage. Diabetes may lead to pulmonary parenchymal damage besides alterations in the vascular system and the alveolar-capillary membrane. Symptoms and damage caused by diabetes are usually underdiagnosed because of the large pulmonary reserves. Pulmonary involvement in diabetes is an area that draws attention in recent years. This attention increases especially with the new Coronavirus disease-2019 (COVID-19) pandemic when worse prognosis is detected in diabetics. In this review, possible mechanisms leading to pulmonary involvement and pulmonary function abnormalities in diabetes, interaction between COVID-19 and diabetes concerning lungs and the basic effects of antidiabetic drugs on the lungs are discussed in the view of the literature.
\end{abstract}

Turk J Int Med 2020;2(3):59-65 DOI: $10.46310 /$ tjim.768962

Keywords: Diabetes mellitus, lungs, pulmonary function, COVID-19, antidiabetic agents

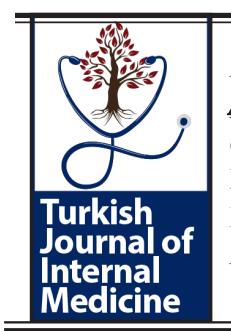




\section{Introduction}

Diabetes mellitus is a chronic disease characterized by hyperglycemia. According to International Diabetes Federation (IDF) approximately 463 million people are diabetic worldwide currently and diabetes increases the risk of early death. IDF estimated 4.2 million deaths due to diabetes and it's complications in $2019 .{ }^{1}$ Diabetes mellitusleads to chronic complications and damages the vascular system, heart, eyes, kidneys and nerves that significantly contribute to morbidity and mortality. The lungs are also predisposed to diabetes' vascular damage, since they have a large vascular network. The alveolar capillary network is the largest microvascular organ with a surface area of $140 \mathrm{~m}^{2}$. Symptoms and disability caused by diabetes develop later in the lungs compared to other organs, because of the larger pulmonary reserves..$^{2-5}$ Pulmonary involvement in diabetes is an area that draws attention in recent years. Nowadays, with the new Coronavirus disease-2019 (COVID-19) pandemic, this attention rises prominently due to the worse prognosis reported in diabetics. In this review, possible involvement mechanisms and functional abnormalities in the lungs in diabetes, interaction between COVID-19 and diabetes concerning lungs and the basic effects of antidiabetic drugs on the lungs are discussed in the view of the literature.

\section{How can diabetes mellitus affect the lungs?}

There are some possible mechanisms concerning pulmonary involvement in diabetes.

\section{Chronic inflammation}

Diabetes leads to chronic low-grade inflammation which is associated with increased levels of inflammatory mediators, such as C-reactive protein (CRP) and interleukin (IL)-6, that may affect the lungs. Inflammation can cause impaired lung function. Type 2 diabetics with inadequate glycemic control are shown to have lower forced expiratory volume in one second (FEV1) and forced vital capacity (FVC) compared to subjects with adequate control, which might be a result of inflammation aggravated with poor glycemic control. ${ }^{5,6}$ Studies conducted in patients with type 2 diabetes mellitus demonstrated that hs-CRP associates negatively with lung function. ${ }^{6,7}$

\section{Insulin resistance and hyperinsulinemia}

Insulin resistance, especially seen in type 2 diabetes, contributes to increased insulin levels which leads to increased airway smooth muscle (ASM) mass and contractility that decreases muscle strength in the long run. Increased respiratory smooth muscle mass also leads to airway hypersensitivity and activation of epithelial mesenchymal trophic unit leading to airway remodeling. ${ }^{8-10}$ Insulin resistance is also thought to affect lung volume and mechanical function via mediators such as leptin. Serum leptin levels are shown to be inversely related to FEV1. ${ }^{5,11,12}$ High glucose concentrations in the airways lead to enhanced responsiveness of ASM to contractile agents. Different studies have shown that hyperglycemia and insulin resistance are closely related to idiopathic pulmonary fibrosis and chronic obstructive pulmonary diseases. ${ }^{3,4}$

\section{Advanced glycation end products}

Because of prolonged hyperglycemia and glucotoxicity, activation of nonenzymatic glycosylation of lung collagen and elastin by advanced glycation end products (AGEs) results in reduced lung elasticity. Nonenzymatic glycosylation of collagen in the lungs makes it less susceptible to proteolysis which accumulates in lung connective tissue and chest wall. ${ }^{5,13}$ Collagen accumulation leads to increased stiffness of both lung parenchyma and chest wall and restrictive functional defects occur. When elastic recoil capacity of the lung is lost, this situation leads to dynamic collapse of small airways during exhalation. AGEs may initiate adaptive immune reactions and reactive oxygen species (ROS) production, which leads to microvascular damages and structural changes like thickening of alveolar epithelial basal laminae. These changes and damages impair lung function. ${ }^{7}$ AGE receptors are commonly found in membranes and cytoplasms of pneumocytes and macrophages in the lungs. When the AGE receptors are stimulated inflammatory response, cytokine production and endothelial vascular permeability increase and lungs' vascular network is damaged. ${ }^{4}$ 


\section{Autonomic neuropathy}

Autonomic neuropathy seen as a complication of diabetes leads to neuroadrenergic denervation of the lungs and respiratory muscles. Neuropathic as well as myopathic changes of respiratory muscles can impair the ventilatory pump efficiency which may contribute to functional defects in the lungs. ${ }^{4,5}$

\section{Pulmonary infections}

In healthy individuals, the glucose concentration in the respiratory tract is lower than blood glucose at a rate of $1 / 12$. Normal range of blood glucose is $70-100 \mathrm{mg} / \mathrm{dL}$. When blood glucose exceeds $120 \mathrm{mg} / \mathrm{dL}$, the airway glucose concentration increases and creates a favorable environment for bacterial growth. Besides, chronic hyperglycemia impairs neutrophil function leading to defects in phagocytosis. All of these defects can facilitate development of pulmonary infections and lung damage in diabetics. ${ }^{4,14}$

\section{Pulmonary involvement in new Coronavirus disease-2019}

Diabetes mellitus leads to inflammation, increased proinflammatory cytokine production and endothelial dysfunction. These facts are also reported in COVID-19 caused by acute respiratory syndrome coronavirus 2 (SARSCoV-2). COVID-19 mostly affects the lungs and is often manifested by severe acute respiratory syndrome. In diabetics, SARS-CoV-2 infection often impairs glycemic control. Immune response is disrupted due to hyperglycemia and viral replication cannot be controlled. IL-6, CRP, ferritin and D-dimer serum levels are shown to be higher in diabetic patients with COVID-19 compared to non-diabetics. These findings may explain the higher cytokine release and tendency to thrombosis in diabetics. The large vascular network in the lungs involved with thrombosis together with cytokine storm may explain the negative prognosis tendency seen in diabetics with COVID-19. In these patients, pneumonia is often more refractory to medical treatments and oxygen support and intensive care monitoring are more frequently required, leading to poor prognosis and increased mortality. ${ }^{15-18}$

\section{Histopathological changes}

Diabetes can cause an injury in the pulmonary microcirculation by increasing vessel wall thickness, similar to vascular injuries seen in other organs. Diabetic alveolar epithelial cells and endothelial capillary basal lamina are shown to be thicker compared to controls. The degree of thickening was shown to correlate significantly with the thickness of basal laminas in renal tubules and muscle capillaries, but not with patient's or diabetes' age..$^{5,19}$

\section{What are the respiratory function abnormalities seen in diabetes?}

\section{Reduced diffusion capacity of lungs for carbonmonoxide}

Diffusion capacity of lungs for carbonmonoxide (DLCO) can be easily measured by lung function tests. DLCO depends on alveolar-capillary membrane conductance and pulmonary capillary blood volume. Diabetes is frequently associated with histopathological alterations such as the thickening of the pulmonary capillary basal lamina and alveolar epithelium both contributing to reduced gas diffusion velocity through the alveolar-capillary membrane. ${ }^{5,20}$ A reduction in the permeability of the alveolar-capillary basement membrane was detected in diabetic patients even without any evidence for DLCO reduction. ${ }^{21}$ Reduction of DLCO in diabetic patients was shown to correlate with other vascular complications of diabetes, like retinopathy and nephropathy. ${ }^{22}$ Affected pulmonary vasculature maylead to redistribution of pulmonary circulation, leading to ventilation/perfusion mismatch, which impaires gas exchange. DLCO changes in diabetic patients can also be due to the autonomic nervous system dysfunction, seen in diabetes as a complication. Reduced DLCO and cardiac autonomic dysfunction are found to be significantly associated which can be determined by heart rate variability measurement. ${ }^{23}$ Lung capillary blood volume was reported to be decreased in patients with type 1 diabetes. ${ }^{24}$

\section{Lung volume reductions}

Diabetes may lead to parenchymal damages as well as alterations in the pulmonary vascular system and the alveolar-capillary membrane. ${ }^{25}$ Inflammatory changes in hyperglycemia can cause pulmonary fibrosis. In a study in which FVB mice with streptozotocin induced type 1 diabetes 
were examined, alveolar septal thickening, inflammatory cell infiltration and marked fibrosis in the interstitium of the lungs were detected. These changes were accompanied by an increase in the markers associated with fibrosis like connective tissue growth factor and fibronectin. Besides an increase in the expression of mRNA of the inflammation and coagulation markers like PAI-1 and tumor necrosis factor (TNF)- $\alpha$ were detected. Lung fibrosis with specific nodular pattern are also reported in diabetic patients. ${ }^{3,5,22}$ Lung volume reductions due to anatomic lung abnormalities in patients with diabetes can partly explain the pulmonary function defects. Tests demonstrating lung mechanical function include dynamic breathing changes in lung elasticity, airflow resistance, and maximal forced spirometric pulmonary function tests (PFT). In practice, $\mathrm{PFTs}$ are influenced by different factors like aging, loss of muscle strength from any cause and obesity. Studies evaluating spirometric PFTs in patients with diabetes have conflicting results some showing decrease in PFTs in diabetics, some not. ${ }^{20,24,27-30}$

\section{Bronchomotor tone and control of ventilation}

Diabetics are shown to have disorders in bronchomotor tone and control of ventilation due to autonomic neuropathy which can cause functional impairment of the respiratory system through damage to the bronchial neuroadrenergic innervation. Defects in bronchial neuroadrenergic innervation can change the ventilatory response to central and peripheral stimuli. While chemosensibility to hypoxia is shown to be depressed in diabetic patients with autonomic neuropathy ${ }^{31}$, there are conflicting results regarding chemosensibility to hypercapnia. The ventilatory response to hypercapnia is reported to be reduced, normal or increased in different diabetic populations with autonomic neuropathy. ${ }^{32,33}$ This heterogenity may be due to differences in the patterns of the autonomic nervous system disturbance, degrees of dysautonomia and intensities of stimuli. ${ }^{34}$ Dysfunction of autonomic innervation and reduction of peripheral and central chemosensibility may be involved in altered perception of breathlessness -which is generally the main symptom- and abnormality in the ventilatory response to exercise. ${ }^{5}$

\section{Respiratory muscle function}

Respiratory muscle function defects may lead to reduced lung volumes, leading to restrictive functional impairment. The respiratory muscle strength is reported to be weakened in diabetics. ${ }^{35}$ In a study conducted in type 2 diabetics, reduction in respiratory muscle strength was found to be inversely correlated with the degree of glycemic control and more prevalent in those with diabetic microvascular complications. ${ }^{36}$ In a study conducted in type 2 diabetics, restrictive pulmonary function was found to be related to glucose metabolism, and presence of nephropathy was shown to increase the risk of restrictive lung disease. $^{37}$

\section{What are the possible effects of antidiabetic agents on the lungs?}

All antidiabetic agents control hyperglycemia via different mechanisms, some of them decreasing insulin resistance. Control of glycemic parameters and metabolic control is important in preventing or delaying diabetes related vascular complications. Some antidiabetic agent groups are thought to have positive effects on possible pulmonary outcomes via different actions, mainly through anti-inflammatory effects. Metformin inhibits the release of proinflammatory cytokines and activation of nuclear factor- $\kappa \mathrm{B}(\mathrm{NF}-\kappa \mathrm{B})^{38}$, reduces CRP. ${ }^{39}$ Glibenclamide is an inhibitor of IL-1 $\beta$ in pancreatic islets. ${ }^{40}$ Thiazolidinediones are agonists for the peroxisome proliferator-activated receptor- $\gamma$ (PPAR- $\gamma)$. They have potent antiinflammatory effects in the lungs ${ }^{41}$ by inhibiting $\mathrm{NF}-\kappa \mathrm{B}$-mediated inflammatory pathways and reducing levels of TNF- $\alpha$ and IL- $6 .{ }^{42}$ Glucagon like peptide 1 analogs stimulate vasodilation and bronchodilation. Dipeptidylpeptidase 4 inhibitors inhibit AGE and receptor (RAGE) gene expressions and proinflammatory pathways. ${ }^{43,44}$

Insulin has anti-inflammatory effects by suppressing the production of ROS and inhibiting proinflammatory transcription factors like $\mathrm{NF}-\kappa \mathrm{B}$, activator protein-1, and early growth response-1. Besides some concerns also exist regarding the potential for pulmonary hazard with chronic use of inhaled insulin due to immunogenic and growth-promoting properties. Inhaled insulin has the potential to induce a concentration- 
dependent ASM contraction via prostaglandins. $4,45,46$

It seems necessary to conduct more clinical studies evaluating the effects of antidiabetic treatment options on the lungs to clarify the specific pulmonary effects of antidiabetic agents, other than glycemic control.

\section{Conclusion}

Diabetes mellitus is a chronic disease that may lead to chronic micro and macrovascular complications. The lungs are the largest microvascular organs with their huge alveolar capillary network. This property makes lungs vulnerable to the harmful effects of diabetes mellitus. Because of the larger pulmonary reserves, symptoms and disability from diabetes may not be diagnosed until subclinical pulmonary dysfunction becomes overt with accompanying situations like aging, smoking, cardiopulmonary diseases and infections like SARS-CoV-2. Periodic monitoring of the respiratory function in patients with diabetes is important by keeping in mind the possible presence of an assault of diabetes mellitus on pulmonary vasculature and parenchyme. Providing good glycemic control and controlling hyperinsulinemia by reducing insulin resistance will allow to reduce or prevent lung-related problems in diabetic patients.

\section{Conflict of interest}

The author declared that there is no potential conflict of interest with respect to the research, authorship, and/or publication of this article.

\section{References}

1. Worldwide toll of diabetes- Individual, social and economic impact, International Diabetes Federation (IDF) atlas, 9th edition [Internet]. Available at: https:// www.diabetesatlas.org/en/. Accessed July 10, 2020.

2. Kaparianos A, Argyropoulou E, Sampsonas F, Karkoulias K, Tsiamita M, Spiropoulos K. Pulmonary complications in diabetes mellitus. Chron Respir Dis. 2008;5(2):101-8. doi: $10.1177 / 1479972307086313$.

3. Hu Y, Ma Z, Guo Z, Zhao F, Wang Y, Cai L, Yang J. Type 1 diabetes mellitus is an independent risk factor for pulmonary fibrosis. Cell Biochem Biophys. 2014 Nov;70(2):1385-91. doi: 10.1007/s12013-014-0068-4.

4. Cazzola M, Rogliani P, Calzetta L, Lauro D, Page C, Matera MG. Targeting Mechanisms Linking COPD to Type 2 Diabetes Mellitus. Trends Pharmacol Sci. 2017 Oct;38(10):940-951. doi: 10.1016/j.tips.2017.07.003.

5. Pitocco D, Fuso L, Conte EG, Zaccardi F, Condoluci C, Scavone G, Incalzi RA, Ghirlanda G. The diabetic lung-a new target organ? Rev Diabet Stud. 2012 Spring;9(1):23-35. doi: 10.1900/RDS.2012.9.23.

6. Dennis RJ, Maldonado D, Rojas MX, Aschner P, Rondón M, Charry L, Casas A. Inadequate glucose control in type 2 diabetes is associated with impaired lung function and systemic inflammation: a cross-sectional study. BMC Pulm Med. 2010 Jul 26;10:38. doi: 10.1186/1471-2466-1038.

7. Röhling M, Pesta D, Markgraf DF, Strassburger K, Knebel B, Burkart V, Szendroedi J, Müssig K, Roden M; GDS study group. Metabolic Determinants of Impaired Pulmonary Function in Patients with Newly Diagnosed Type 2 Diabetes Mellitus. Exp Clin Endocrinol Diabetes. 2018 Sep;126(9):584-589. doi: 10.1055/a-0653-7135.

8. Singh S, Prakash YS, Linneberg A, Agrawal A. Insulin and the lung: connecting asthma and metabolic syndrome. J Allergy (Cairo). 2013;2013:627384. doi: 10.1155/2013/627384.

9. Kim HK, Lee $\mathrm{CH}$, Kim JM, Ayush O, Im SY, Lee HK. Biphasic late airway hyperresponsiveness in a murine model of asthma. Int Arch Allergy Immunol. 2013;160(2):173-83. doi: 10.1159/000341645.

10. Zuyderduyn S, Sukkar MB, Fust A, Dhaliwal S, Burgess JK. Treating asthma means treating airway smooth muscle cells. Eur Respir J. 2008 Aug;32(2):265-74. doi: 10.1183/09031936.00051407.

11. O'Donnell CP, Tankersley CG, Polotsky VP, Schwartz AR, Smith PL. Leptin, obesity, and respiratory function. Respir Physiol. 2000 Feb;119(2-3):163-70. doi: 10.1016/ s0034-5687(99)00111-5.

12. Sin DD, Man SF. Impaired lung function and serum leptin in men and women with normal body weight: a population based study. Thorax. 2003 Aug;58(8):695-8. doi: 10.1136/thorax.58.8.695.

13. Cavan DA, Parkes A, O'Donnell MJ, Freeman W, Cayton RM. Lung Function and Diabetes. Respir Med. 1991 May;85(3):257-8. doi: 10.1016/s0954-6111(06)80092-2.

14. Baker EH, Baines DL. Airway Glucose Homeostasis: A New Target in the Prevention and Treatment of Pulmonary Infection. Chest. 2018 Feb;153(2):507-514. doi: 10.1016/j.chest.2017.05.031.

15. Sardu C, Gambardella J, Morelli MB, Wang X, Marfella R, Santulli G. Hypertension, Thrombosis, Kidney Failure, and Diabetes: Is COVID-19 an Endothelial Disease? A Comprehensive Evaluation of Clinical and Basic Evidence. J Clin Med. 2020 May 11;9(5):E1417. doi: 10.3390/jcm9051417.

16. Hussain A, Bhowmik B, do Vale Moreira NC. COVID-19 and diabetes: Knowledge in progress. Diabetes Res Clin Pract. 2020 Apr;162:108142. doi: 10.1016/j. diabres.2020.108142.

17. Pal R, Bhadada SK. COVID-19 and diabetes mellitus: An unholy interaction of two pandemics. Diabetes Metab Syndr. 2020 May 6;14(4):513-517. doi: 10.1016/j. dsx.2020.04.049.

18. Guo W, Li M, Dong Y, Zhou H, Zhang Z, Tian C, Qin 
R, Wang H, Shen Y, Du K, Zhao L, Fan H, Luo S, Hu D. Diabetes is a risk factor for the progression and prognosis of COVID-19. Diabetes Metab Res Rev. 2020 Mar 31:e3319. doi: 10.1002/dmrr.3319.

19. Weynand B, Jonckheere A, Frans A, Rahier J. Diabetes Mellitus Induces a Thickening of the Pulmonary Basal Lamina. Respiration. 1999;66(1):14-9. doi: 10.1159/000029331.

20. Goldman MD. Lung dysfunction in diabetes. Diabetes Care. 2003 Jun;26(6):1915-8. doi: 10.2337/ diacare.26.6.1915.

21. Ozsahin K, Tugrul A, Mert S, Yüksel M, Tugrul G. Evaluation of pulmonary alveolo-capillary permeability in Type 2 diabetes mellitus: using technetium 99mTc-DTPA aerosol scintigraphy and carbon monoxide diffusion capacity, J Diabetes Complications. 2006;20(4):205-9. doi: 10.1016/j.jdiacomp.2005.07.003.

22. Marvisi M, Bartolini L, del Borrello P, Brianti M, Marani G, Guariglia A, Cuomo A. Pulmonary function in non-insulin-dependent diabetes mellitus. Respiration. 2001;68(3):268-72. doi: 10.1159/000050509.

23. Pitocco D, Santangeli P, Fuso L, Zaccardi F, Longobardi A, Infusino F, Incalzi RA, Lanza GA, Crea F, Ghirlanda G. Association between reduced pulmonary diffusing capacity and cardiac autonomic dysfunction in type 1 diabetes. Diabet Med. 2008 Nov;25(11):1366-9. doi: 10.1111/j.1464-5491.2008.02571.x.

24. Fuso L, Cotroneo P, Basso S, De Rosa M, Manto A, Ghirlanda G, Pistelli R: Postural variations of pulmonary diffusing capacity in insulin-dependent diabetes mellitus. Chest. 1996 Oct;110(4):1009-13. doi: 10.1378/ chest.110.4.1009.

25. Farina J, Furio V, Fernandez-Acenero MJ, Muzas MA. Nodular fibrosis of the lung in diabetes mellitus. Virchows Arch. 1995;427(1):61-3. doi: 10.1007/BF00203738.

26. Gribbin J, Hubbard R, Smith C. Role of diabetes melli tus and gastro-oesophageal reflux in the aetiology of idiopathic pulmonary fibrosis. Respir Med. 2009 Jun;103(6):927-31. doi: 10.1016/j.rmed.2008.11.001.

27. Schnack C, Festa A, Schwarzmaier-D'Assie A, Haber $P$, Schernthaner G. Pulmonary dysfunction in type 1 diabetes in relation to metabolic long-term control and to incipient diabetic nephropathy. Nephron. 1996;74(2):395400. doi: 10.1159/000189342.

28. Mori H, Okubo M, Okamura M, Yamane K, Kado $S$, Egusa $G$, Hiramoto $T$, Hara $H$, Yamakido $M$. Abnormalities of pulmonary function in patients with noninsulin-dependent diabetes mellitus. Intern Med. 1992 Feb;31(2):189-93. doi: 10.2169/internalmedicine.31.189.

29. Ozmen B, Celik P, Yorgancioglu A, Ozmen B, Ozmen D, Cok G. Pulmonary function parameters in patients with diabetes mellitus. Diabetes Res Clin Pract. 2002 Sep;57(3):209-11. doi: 10.1016/s0168-8227(02)00057-8.

30. Benbassat CA, Stern E, Kramer M, Lebzelter J, Blum I, Fink G. Pulmonary function in patients with diabetes mellitus. Am J Med Sci. 2001 Sep;322(3):127-32. doi: 10.1097/00000441-200109000-00003.

31. Nishimura M, Miyamoto K, Suzuki A, Yamamoto $H$, Tsuji M, Kishi F, Kawakami Y. Ventilatory and heart rate responses to hypoxia and hypercapnia in patients with diabetes mellitus. Thorax. 1989 Apr;44(4):251-7. doi: 10.1136/thx.44.4.251.

32. Soler NG, Eagleton LE. Autonomic neuropathy and the ventilatory responses of diabetics to progressive hypoxemia and hypercarbia. Diabetes. 1982 Jul;31(7):60914. doi: 10.2337/diab.31.7.609.

33. Wanke T, Abrahamian H, Lahrmann H, Formanek D, Merkle M, Auinger M, Zwick H, Irsigler K. No effect of naloxone on ventilatory response to progressive hypercapnia in IDDM patients. Diabetes. 1993 Feb;42(2):282-7. doi: 10.2337/diab.42.2.282.

34. Tantucci C, Bottini P, Fiorani C, Dottorini ML, Santeusanio F, Provinciali L, Sorbini CA, Casucci G. Cerebrovascular reactivity and hypercapnic respiratory drive in diabetic autonomic neuropathy. J Appl Physiol. 2001 Mar;90(3):889-96. doi: 10.1152/jappl.2001.90.3.889.

35. Scano G, Seghieri G, Mancini M, Filippelli M, Duranti R, Fabbri A, Innocenti F, Iandelli I, Misuri G. Dyspnoea, peripheral airway involvement and respiratory muscle effort in patients with type I diabetes mellitus under good metabolic control. Clin Sci (Lond). 1999 May;96(5):499506.

36. Fuso L, Pitocco D, Longobardi A, Zaccardi F, Contu C, Pozzuto C, Basso S, Varone F, Ghirlanda G, Antonelli Incalzi R. Respiratory muscle strength and endurance in type 2 diabetes mellitus. Diabetes Metab Res Rev. 2012 May;28(4):370-5. doi: 10.1002/dmrr. 2284.

37. Kopf S, Groener JB, Kender Z, Fleming T, Brune M, Riedinger C, Volk N, Herpel E, Pesta D, Szendrödi J, Wielpütz MO, Kauczor HU, Katus HA, Kreuter M, Nawroth PP. Breathlessness and Restrictive Lung Disease: An Important Diabetes-Related Feature in Patients with Type 2 Diabetes. Respiration. 2018;96(1):29-40. doi: 10.1159/000488909.

38. Kikuo Isoda 1, James L Young, Andreas Zirlik, Lindsey A MacFarlane, Naotake Tsuboi, Norbert Gerdes, Uwe Schönbeck, Peter Libby. Metformin Inhibits Proinflammatory Responses and Nuclear factorkappaB in Human Vascular Wall Cells. Arterioscler Thromb Vasc Biol. 2006 Mar;26(3):611-7. doi:10.1161/01. ATV.0000201938.78044.75.

39. Haffner S, Temprosa M, Crandall J, Fowler S, Goldberg $\mathrm{R}$, Horton E, Marcovina S, Mather K, Orchard T, Ratner R, Barrett-Connor E; Diabetes Prevention Program Research Group. Intensive lifestyle intervention or metformin on inflammation and coagulation in participants with impaired glucose tolerance. Diabetes. 2005 May;54(5):1566-72. doi: 10.2337/diabetes.54.5.1566.

40. Donath MY. Targeting Inflammation in the Treatment of Type 2 Diabetes: Time to Start. Nat Rev Drug Discov. 2014 Jun;13(6):465-76. doi: 10.1038/nrd4275.

41. Birrell MA, Patel HJ, McCluskie K, Wong S, Leonard T, Yacoub MH, Belvisi MG. PPAR-gamma Agonists as Therapy for Diseases Involving Airway Neutrophilia Eur Respir J. 2004 Jul;24(1):18-23. doi: 10.1183/09031936.04.00098303.

42. Ceriello A. Thiazolidinediones as Anti-Inflammatory and Anti-Atherogenic Agents. Diabetes Metab Res Rev. Jan-Feb 2008;24(1):14-26. doi: 10.1002/dmrr.790.

43. Nguyen DV, Linderholm A, Haczku A, Kenyon N. Glucagon-like Peptide 1: A Potential AntiInflammatory Pathway in Obesity-Related Asthma. Pharmacol Ther. 2017 Dec;180:139-143. doi: 10.1016/j. pharmthera.2017.06.012.

44. Rogliani P, Calzetta L, Capuani B, Facciolo F, Cazzola M, Lauro D, Matera MG. Glucagon-Like Peptide 1 Receptor: A Novel Pharmacological Target for Treating Human Bronchial Hyperresponsiveness. Am J Respir 
Cell Mol Biol. 2016 Dec;55(6):804-814. doi: 10.1165/ rcmb.2015-03110C.

45. Camus P. Inhaled Insulin in Clinical Practice A Focus on Pulmonary Safety. US Endocrinology, 2007;(1):44-6, doi: 10.17925/USE.2007.00.1.44.

46. Schaafsma D, Gosens R, Ris JM, Zaagsma J, Meurs H,
Nelemans SA. Insulin Induces Airway Smooth Muscle Contraction. Br J Pharmacol. 2007 Jan;150(2):136-42. doi: 10.1038/sj.bjp.0706985. 